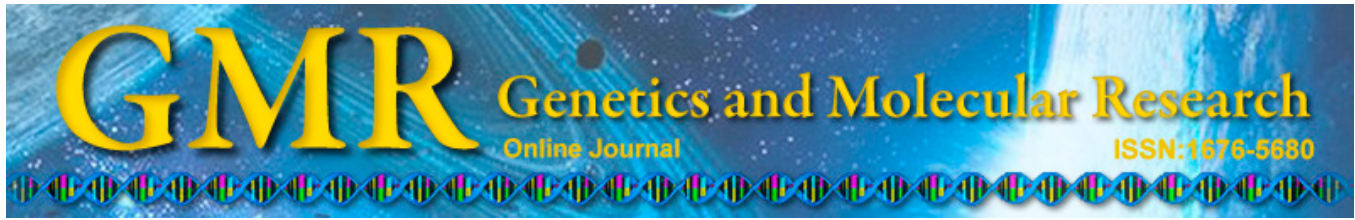

\title{
Screening and identification of microsatellite markers associated with cold tolerance in Nile tilapia Oreochromis niloticus
}

\author{
H.P. Zhu, Z.G. Liu, M.X. Lu, F.Y. Gao, X.L. Ke and Z.H. Huang \\ Key Laboratory of Tropical \& Subtropical Fishery Resource Application \& \\ Cultivation, Ministry of Agriculture, Pearl River Fisheries Research Institute, \\ Chinese Academy of Fishery Sciences, Guangzhou, China \\ Corresponding author: M.X. Lu \\ E-mail: mx-lu@163.com
}

Genet. Mol. Res. 14 (3): 10308-10314 (2015)

Received December 9, 2014

Accepted May 8, 2015

Published August 28, 2015

DOI http://dx.doi.org/10.4238/2015.August.28.16

\begin{abstract}
Tilapia is an important fish cultured in tropical and subtropical areas. Cold sensitivity limits the expansion of tilapia culture into colder regions of the world, and mass mortalities of cultured tilapia have been reported due to severe cold currents in winter. Since the late 1990s, several strains of Nile tilapia have been domesticated to improve the ability to adapt to low temperatures. Previous studies revealed that these varieties were more cold-tolerant than the founder population and overwintered naturally well in ponds in the westsouth area of Guangdong Province. In this study, to develop tilapia strains with improved cold tolerance for breeding programs through marker-assisted selection, two microsatellite markers, UNH916 and UNH999, showed complete co-segregation with cold tolerance among the polymorphic microsatellite primers. Our results provide a foundation for identifying resistant gene(s) linked with these markers, as well as identifying simple sequence repeat markers associated with cold tolerance that can be used for maker-assisted selection programs
\end{abstract}


in tilapia breeding to increase the growing range and productivity of tilapia aquaculture.

Key words: Cold tolerance; Low temperature; Microsatellite; Oreochromis niloticus

\section{INTRODUCTION}

Tilapia is one of the most widely cultured food fish species worldwide and has been introduced to more than 80 countries because of their plasticity and adaptability to changing environmental conditions, as well as the ability to feed at different trophic levels (Molnar et al., 2008). The most important aspect of tilapia is that they are tropical fishes that are sensitive to cold, and thus cannot survive naturally in winter in more temperate climates. Cold sensitivity is a limiting factor in expanding tilapia culture into colder regions of the world. In China, because of the climate, outdoor culture of tilapia is limited to southern regions, in which aquaculture is flourishing. The extreme climate recorded in recent years has resulted in serious economic losses to the fishery industry. Particularly, the occurrence of a rare cold disaster severely damaged aquaculture because of continuous extreme low temperatures in southern China in January 2008. Fishery economic losses in the Guangdong Province have totaled more than US\$ 1.03 billion, and more than 484.5 thousand tons of fish perished (Cai and Liu, 2008). To improve cold tolerance and reduce the production costs of overwintering, studies of the fish cold tolerance trait is an important research area.

The cold tolerance trait of fish has widely examined, with most studies focusing on physiological factors such as blood cells, cell membranes, and the enzyme esterase (Buda et al., 1994; Los and Murata, 2004; Zerai et al., 2010). One limitation of cold tolerance research in fish is the lack of well-defined lines contrasting with respect to cold tolerance (Sun and Liang, 2004). At the end of the 1990s, several lines of Nile tilapia have been domesticated to improve the ability to adapt to low temperatures; some of these stocks are highly resistant to low temperatures and are overwinter naturally well in ponds in the west-south area of Guangdong Province. Analysis of DNA methylation revealed a statistically significant decrease in the total methylation levels in the cold-resistance tilapia stain compared with the control; the decreased DNA methylation levels suggested that the genomic DNA methylation levels were altered during the successive cold stress over multi-generations in tilapia (Zhu et al., 2013). In this study, we isolated the molecular marker associated with cold tolerance from tilapia adapted to lower temperatures. Our results increase the understanding of the genetic control of cold tolerance and revealed potential target markers to be manipulated by marker-assisted selection in tilapia breeding programs.

\section{MATERIAL AND METHODS}

\section{Source of samples}

Nile tilapia (Oreochromis niloticus) breeders used in the present study, based on prior records of good performance indicating high cold tolerance ability (Zhu et al., 2013), were obtained from the Gaoyao Aquaculture Germplasm Conservation Station, Pearl River 
Fisheries Research Institute, Chinese Academy of Fishery Sciences. These fish originated from the selected strains $\left(\mathrm{F}_{8}\right.$ generation with a natural mortality temperature of $\left.8.5^{\circ}-7.3^{\circ} \mathrm{C}\right)$ that overwintered naturally well in ponds in the middle-west area of Guangdong Province. Cold sensitivity strains with natural mortality temperatures of $9.8^{\circ}-8.6^{\circ} \mathrm{C}$ were included in the control groups. Intra-specific crossing was performed between the cold-resistance tilapia strain and the cold-sensitive strain, and the F2 generation was obtained from F1 hybrids for association analysis between the cold tolerance characteristics and microsatellite markers. During the winter, F2 individuals (mean weight, $90.26 \pm 20.83 \mathrm{~g}$ ) were tagged with passive integrated transponder tags and stocked into a pond to overwinter naturally. After the winter, survivors were assumed to have cold tolerance characteristics, while dead individuals were assumed to be sensitive to cold.

\section{Genomic DNA extraction}

For microsatellite analysis, non-destructive sampling was conducted by using the fin clips for DNA extraction without having to sacrifice the animal. Genomic DNA was isolated and purified using standard phenol/chloroform procedures (Sambrook and Russell, 2001).

\section{Microsatellite analysis}

Microsatellite loci were isolated from the genomic DNA of Nile tilapia using the method described by Guo and Gui (2008). Briefly, 56 pairs of microsatellite primers for the flanking regions of each locus were designed based on the sequences reported in the GenBank database and by Lee et al. (2005). Primers were synthesized by the ShengGong Biological Engineering Technology (Shanghai, China). Polymerase chain reaction amplification was performed in a $20-\mu \mathrm{L}$ mixture containing $20 \mathrm{ng}$ genomic DNA template, $1 \mathrm{X}$ polymerase chain reaction buffer, $100 \mu \mathrm{M}$ of each dNTP, $1.5 \mathrm{mM} \mathrm{MgCl}_{2}, 0.2 \mu \mathrm{M}$ of each primer, and $0.5 \mathrm{U}$ Taq DNA polymerase. Double-distilled water was added to a final volume of $20 \mu \mathrm{L}$. The thermal cycling conditions for amplification of microsatellite DNA consisted of an initial denaturation step at $94^{\circ} \mathrm{C}$ for $4 \mathrm{~min}$, followed by denaturation for 25 cycles at $94^{\circ} \mathrm{C}$ for $30 \mathrm{~s}$, annealing at an optimized temperature for $30 \mathrm{~s}$, and extension at $72^{\circ} \mathrm{C}$ for $30 \mathrm{~s}$; the extension step was conducted at $72^{\circ} \mathrm{C}$ for $7 \mathrm{~min}$ in the last cycle. Amplification products were separated by $8 \%$ polyacrylamide gel electrophoresis and stained with silver nitrate.

\section{Identification of markers associated with cold tolerance}

Genomic DNA samples of the grandparent and F2 generations were extracted for association analysis between cold tolerance characteristics and microsatellite markers. The F2 generation was divided into 3 groups; one group included fish that survived at a water temperature of $8^{\circ} \mathrm{C}$ and were assumed to have cold tolerance characteristics (cold-tolerant individuals), while the second group included individuals that died at water temperature of $10^{\circ} \mathrm{C}$ (cold-sensitive individuals). The third group included individuals that died at water temperatures of $8-10^{\circ} \mathrm{C}$; these fish were not used for genotyping. According to the genotypes of the parents and the F2 generation groups, Pearson's $\chi^{2}$ analysis was performed to measure the association between cold tolerance characteristics and microsatellite marker genotypes; $\mathrm{P}$ values less than 0.05 were considered to be statistically significant. 


\section{RESULTS}

A total of 56 primer pairs were selected for identifying polymorphisms between coldtolerant lines and cold-sensitive lines. Sixteen primer pairs showed consistent polymorphic amplification and were used for co-segregation analysis (Table 1). Among these polymorphic microsatellite primers, 2 primers, UNH916 and UNH999, showed differential allelic segregation between the cold-tolerant lines and cold-sensitive lines. The 136-bp allele of UNH916 was observed more frequently in cold-tolerant individuals, while the 160-bp allele was present in cold-sensitive individuals. Cold-tolerant individuals showed a 110-bp allele at UNH999, but cold-sensitive individuals carried a 106-bp allele.

Table 1. List of polymorphic microsatellite primers between parents.

\begin{tabular}{|c|c|c|}
\hline Primer name & Sequence (5'-3') & $\operatorname{Tm}\left({ }^{\circ} \mathrm{C}\right)$ \\
\hline \multirow[t]{2}{*}{ UNH106 } & F: CCTTCAGCATCCGTATAT & 58 \\
\hline & R: GTCTCTTTCTCTCTGTCACAAG & \\
\hline \multirow[t]{2}{*}{ UNH214 } & F: TTCCATAATTGCTTTCTG & 57 \\
\hline & R: GCACGTTTTCCATCACTTCAA & \\
\hline \multirow[t]{2}{*}{ UNH868 } & F: TCCTTGTTCAGACCTTGTGG & 54 \\
\hline & R: AGCCAGGCTGAAAGGAAATA & \\
\hline \multirow[t]{2}{*}{ GM271 } & F: GCAGCTGGATCAGTCTCTG & 60 \\
\hline & R: TGGGAAGTCGTTCATACAAAG & \\
\hline \multirow{2}{*}{ UNH974 } & F: GCACGTCTGAGAGTGTGGAA & 52 \\
\hline & R: CAGCTTTCACACCAGCCTAA & \\
\hline \multirow[t]{2}{*}{ UNH907 } & F: CAGGACCGACTCTGCAAGAT & 52 \\
\hline & R: GAGCTCTTTTGTTGTTCAAAATC & \\
\hline \multirow{2}{*}{ UNH197 } & F: CAGGATGGTGAGATGTTT & 58 \\
\hline & R: TTAAGTGGAAGAAGTCAATG & \\
\hline \multirow[t]{2}{*}{ UNH998 } & F: TCAATTGGTTTTACAGGAACACA & 62 \\
\hline & R: GCTGAGGTCAGCTTACATGTCT & \\
\hline \multirow[t]{2}{*}{ UNH957 } & F: CTCCGTGACACCAAGCTTTC & 63 \\
\hline & R: ATGGCATCCACTACAAGCTG & \\
\hline \multirow[t]{2}{*}{ UNH940 } & F: TTGGCCACATCTTTTTGTTG & 60 \\
\hline & R: TCACACGTAAACTGTTGCAT & \\
\hline \multirow[t]{2}{*}{ UNH855 } & F: ACTCCCGCTGTTGCTGTTAG & 55 \\
\hline & R: GAGGGGAGCCTACAACGTAA & \\
\hline \multirow[t]{2}{*}{ UNH1009 } & F: CCATCTGCATGCTGTAAGACA & 59 \\
\hline & R: TCCCATTTGTCAGGTTCAGG & \\
\hline \multirow[t]{2}{*}{ UNH907 } & F: CAGGACCGACTCTGCAAGAT & 52 \\
\hline & R: GAGCTCTTTTGTTGTTCAAAATC & \\
\hline \multirow[t]{2}{*}{ UNH1004 } & F: CATCTGAGTCACGCAGGTTC & 55 \\
\hline & R: GCTGAGGTGAGTGTGATGGA & \\
\hline \multirow[t]{2}{*}{ UNH916 } & F: TCCAAACTTATTCCGTGGACA & 52 \\
\hline & R: ATGGCTGAGTTTGCAGACAG & \\
\hline \multirow{2}{*}{ UNH999 } & F: TGCAAAGTCACAAATCCACAA & 55 \\
\hline & R: CTCCCATTCATTACCCCAAA & \\
\hline
\end{tabular}

The list of the F2 generation individuals selected for genotyping is shown in Table 2. Based on the low mortally temperature, individuals were classified as cold-tolerant, cold-sensitive, and moderately cold-sensitive. Pearson $\chi^{2}$ analysis showed that the microsatellite loci were highly associated with cold tolerance $(\mathrm{P}<0.001)$ based on the result of allele segregation in the F2 generation. The segregation distortion at the 5.36\% level for the UNH916 and 4.12\% level for UNH999 occurred more frequently in cold-sensitive individuals. 
Table 2. List of F2 generation individuals selected for genotyping.

\begin{tabular}{lcc}
\hline Family & Number of cold-tolerant individuals (survival at $8^{\circ} \mathrm{C}$ ) & Number of cold-sensitive individuals (mortality at $10^{\circ} \mathrm{C}$ ) \\
\hline 1 & 32 & 57 \\
2 & 48 & 25 \\
3 & 21 & 28 \\
4 & 51 & 89 \\
5 & 62 & 108 \\
6 & 34 & 46 \\
7 & 27 & 58 \\
8 & 39 & 26 \\
9 & 32 & 54 \\
\hline
\end{tabular}

\section{DISCUSSION}

Tilapia is sensitive to low temperatures, and under prolonged or repeated exposure, stopping food intake, stunting, and death are commonly observed. Low temperature is one of the major limiting factors inhibiting the introduction and distribution of tilapia to temperate and high-elevation areas. Several studies have reported the cold-hardy capacity and the identification of simple sequence repeat markers in Nile tilapia. For example, Khater (1985) and Khater and Smitherman (1988) reported that cold tolerance differs among the Egypt, Ghana, and Ivory Coast strains of Nile tilapia. This indicates that the further the geographic location from the equator, the more cold-tolerant the strain of Nile tilapia, and natural selection affects cold tolerance in tilapia. Li et al. (2002) evaluated the cold tolerance of 3 strains (GIFT, Sudan 78, Egypt 88) of Nile tilapia and found that the GIFT line (low lethal temperature ranging from $8.4^{\circ}-11^{\circ} \mathrm{C}$ ) was less tolerant to low temperature than the other 2 strains; there was no difference with respect to temperature tolerance between the Sudan 78 (low lethal temperature ranging from $7.4^{\circ}-9.8^{\circ} \mathrm{C}$ ) and the Egypt 88 strains (low lethal temperature ranging from $7.4^{\circ}$ $11^{\circ} \mathrm{C}$ ). Under indoor artificially low-temperature stress, the results showed that the correlation between semi-lethal low temperature and mortality was significant in 8 strains of tilapia and 15 hybridized tilapia varieties (Lin et al., 2011). Cnaani et al. (2000) reported no correlation between cold tolerance and fish size (23-105 mm standard length) in the species Oreochromis mossambicus, Oreochromis aureus, and their hybrids. In the present study, cold-tolerant individuals survived at a water temperature of $8^{\circ} \mathrm{C}$, while cold-sensitive individuals died when the pool water temperature reached $11^{\circ} \mathrm{C}$.

Molecular markers for cold tolerance in tilapia are largely unknown, with the exception of a microsatellite locus identified by Cnaani et al. (2003). In the 2 unrelated F2 families of interspecific tilapia hybrids (O. mossambicus x $O$. aureus), genetic linkage analysis revealed that microsatellite DNA markers UNH879 within linkage group 23, were the most strongly associated with cold tolerance (Cnaani et al., 2003). In this study, 2 microsatellite markers for cold tolerance were identified in Nile tilapia by Pearson $\chi^{2}$ analysis. Among these, UNH916 and UNH999 were located in linkage group 6 and in linkage group 18, respectively, (Lee et al., 2005) and accounted for 5.36 and $4.12 \%$ of the observed phenotypic variation, respectively. This may have been caused by genetic, physiological, and environmental factors. Segregation distortion is commonly observed in mapping populations, potentially because of sampling techniques or biological selection, and typically impedes the process of genetic map construction (Sundin et al., 2005). 
Identification of these markers is an important step in the development of molecular marker-assisted breeding programs to detect quantitative trait loci for cold tolerance and provides a foundation for isolating the gene(s) underlying cold tolerance in tilapia. These markers associated with cold tolerance are new and promising loci that can be used to increase the understanding of genetic mechanisms. Future studies using these markers will continue to examine whether cold tolerance differs between these lines and how tolerance is mechanistically regulated.

\section{Conflicts of interest}

The authors declare no conflict of interest.

\section{ACKNOWLEDGMENTS}

Research supported by grants from the National Natural Science Foundation of China (Grant \#31001108), the Natural Science Foundation of Guangdong Province, China (Grant \#9451038001003595), the China Agriculture Research System (Grant \#CARS-49), and the Special Scientific Research Funds for Central Non-profit Institutes, Chinese Academy of Fishery Sciences (Grant \#2012A0404).

\section{REFERENCES}

Buda C, Dey I, Balogh N, Horvath LI, et al. (1994). Structural order of membranes and composition of phospholipids in fish brain cells during thermal acclimatization. Proc. Natl. Acad. Sci. U. S. A. 91: 8234-8238.

Cai YC and Liu FY (2008). Risk analysis of cold disaster of fishery in Guangdong Province in 2008. Ocean Fish. 4: 7-9.

Cnaani A, Gall GAE and Hulata G (2000). Cold tolerance of tilapia species and hybrids. Aquacult. Int. 8: 289-298.

Cnaani A, Hallerman EM, Ron M, Weller JI, et al. (2003). Detection of a chromosomal region with two quantitative trait loci, affecting cold tolerance and fish size, in an F2 tilapia hybrid. Aquaculture 223: 117-128.

Guo W and Gui JF (2008). Microsatellite marker isolation and cultured strain identification in Carassius auratus gibelio. Aquacult. Int. 16: 497-510.

Khater AA (1985). Identification and comparison of three tilapia Nilotica strains for selected aquacultural traits. Doctoral thesis, Auburn University, Auburn.

Khater AA and Smitherman RO (1988). Cold Tolerance and Growth of Three Strains of Oreochromis niloticus. In: The Second International Symposium on Tilapia in Aquaculture (Pullin RSV, Bhukaswan T, Tonguthai K and Maclean JL, eds.). ICLARM Conference Proceeding 15, Department of Fisheries, Bangkok, Thailand and International Center for Living Aquatic Resources Management, Manila, 215-218.

Lee BY, Lee WJ, Streelman JT, Carleton KL, et al. (2005). A second-generation genetic linkage map of tilapia (Oreochromis spp.). Genetics 170: 237-244.

Li SF, Li CH, Madan D, Florabelle G, et al. (2002). Cold tolerance of three strains of Nile tilapia, Oreochromis niloticus, in China. Aquaculture 213: 123-129.

Lin Y, Lu QX, Yang HZ, Chen Z, et al. (2011). Analysis of cold hardy capacity in eight strains tilapia and their hybridizations. Acta Agric. Boreali-Sin. 26: 278 -282.

Los DA and Murata N (2004). Membrane fluidity and its roles in the perception of environmental signals. Biochim. Biophys. Acta 1666: 142-157.

Molnar JL, Gamboa RL, Revenga C and Spalding MD (2008). Assessing the global threat of invasive species to marine biodiversity. Front. Ecol. Environ. 6: 485-492.

Sambrook J and Russell DW (2001). Molecular Cloning: A laboratory Manual (3rd edn.). Cold Spring Harbor Laboratory Press, Cold Spring Harbor, 468-470.

Sun XW and Liang LQ (2004). A genetic linkage map of common carp (Cyprinus carpio L.) and mapping of a locus associated with cold tolerance. Aquaculture 238: 165-172. 
Sundin K, Brown KH, Drew RE, Nichols KM, et al. (2005). Genetic analysis of a development rate QTL in backcrosses of clonal rainbow trout, Oncorhynchus mykiss. Aquaculture 247: 75-83.

Zerai DB, Fitzsimmons KM and Collier RJ (2010). Transcriptional response of delta-9-desaturase gene to acute and chronic cold stress in Nile tilapia, Oreochromis niloticus. J. World Aquacult. Soc. 41: 800-806.

Zhu HP, Lu MX, Huang ZH, Gao FY, et al. (2013). Effect of low temperature on genomic DNA methylation in Nile tilapia (Oreochromis niloticus). J. Fish. China 37: 1460-1467. 